\title{
The Relationship between Emotional Quotient and the Acquisition of Basic Skill Among Primary School Children
}

\begin{abstract}
Studies have shown that emotional intelligence is twice as important as IQ for outstanding performance (Wright, 2002). With that statement, the focus is now on children in schools where we educate them with one objective in mind: their success. In the past IQ had always been associated with success, so the question now is, can EQ make the difference? According to Goleman (1995), IQ alone is no more the measure of success; it only accounts for $20 \%$, and the rest goes for emotional, social Intelligences and luck. Therefore it is the objective of this study to find out whether there is a relationship between EQ and children's acquisition of basic skills. A total of 344 primary school children (Year 1 and Year 2) from Kuala Terengganu made up the respondents. They are from the academically weak classes. Out of this sample $3.8 \%$ are those who could not read, write or do Arithmetic. Among these students, 3.2\% had problems in Bahasa Melayu and 3.8\% had problems in Arithmetic. The study utilized the descriptive correlational method. Data were collected using the EQ questionnaire, a modified version of Goleman EQ questionnaire and the reliability using the Cronbach Alpha is .81. The preliminary findings indicated that there is a positive correlation between EQ and basic skills acquisition ( $\mathrm{r}=.47$,pStudies have shown that emotional intelligence is twice as important as IQ for outstanding performance (Wright, 2002). With that statement, the focus is now on children in schools where we educate them with one objective in mind: their success. In the past IQ had always been associated with success, so the question now is, can EQ make the difference? According to Goleman (1995), IQ alone is no more the measure of success; it only accounts for $20 \%$, and the rest goes for emotional, social Intelligences and luck. Therefore it is the objective of this study to find out whether there is a relationship between EQ and children's acquisition of basic skills. A total of 344 primary school children (Year 1 and Year 2) from Kuala Terengganu made up the respondents. They are from the academically weak classes. Out of this sample $3.8 \%$ are those who could not read, write or do Arithmetic. Among these students, 3.2\% had problems in Bahasa Melayu and 3.8\% had problems in Arithmetic. The study utilized the descriptive correlational method. Data were collected using the EQ questionnaire, a modified version of Goleman EQ questionnaire and the reliability using the Cronbach Alpha is .81. The preliminary findings indicated that there is a positive correlation between EQ and basic skills acquisition $(\mathrm{r}=.47, \mathrm{p})$
\end{abstract}

Keyword: Relationship, Emotional Quotient, Acquisition, Basic Skill, Primary School Children 